\title{
LETRAMENTO DE SURDOS UNIVERSITÁRIOS NO BRASIL: O BILINGUISMO EM QUESTÃO
}

\author{
LITERACIDAD SORDA EN LA UNIVERSIDAD EN BRASIL: BILINGÜISMO EN \\ CUESTIÓN
}

\author{
LITERACY OF DEAF UNIVERSITY STUDENTS IN BRAZIL: BILINGUALISM IN \\ QUESTION
}

\author{
Aline Olin Goulart DARDE ${ }^{1}$ \\ Ana Paula de Oliveira SANTANA ${ }^{2}$
}

RESUMO: O acesso à Educação Superior (ES) no Brasil expandiu-se considerando as modificações ocorridas com as políticas inclusivas, bem como às voltadas especificamente para os surdos. Assim, há de se considerar que os surdos, que atualmente, frequentam o ES trazem o legado das práticas pedagógicas que foram submetidos na Educação Básica, bem como o capital cultural "transmitido". Nesse sentido, o objetivo deste estudo é compreender as condições de letramento do surdo universitário, relacionando-as a sua inserção na cultura escrita e as implicações para a permanência na universidade. É uma pesquisa qualitativa, tratando-se de um estudo de caso de dois estudantes surdos de uma universidade pública do sul do país. A leitura e a escrita dos gêneros acadêmicos são realizadas geralmente na universidade, pois a produção desses gêneros é inerente à instituição universitária. Sob uma perspectiva bakhtiniana, discute-se a apropriação de gêneros secundários na esfera do conhecimento em que são constituídos: na universidade. Conclui-se que o fato dos sujeitos não dominarem de forma proficiente a Língua Portuguesa na modalidade escrita (L2) não interferiu a permanência e o sucesso acadêmico dos surdos envolvidos nessa pesquisa quando imersos a um contexto educativo universitário em que a Libras é priorizada. Essa falta de domínio não impediu o ingresso na ES, em nível de graduação e, posteriormente, na pós-graduação e de apresentarem desempenho acadêmico compatível com a complexidade exigida em tais níveis de educação, muito embora as práticas de letramento dos sujeitos e a transmissão de capital cultural tenham se revelado um diferencial nesse processo para o domínio da L2.

PALAVRAS-CHAVE: Surdos. Universitários. Letramento. Capital cultural. Permanência.

RESUMEN: El acceso a la educación superior (ES) en Brasil se ha expandido teniendo en cuenta los cambios que se han producido con las políticas inclusivas, así como aquellos específicamente dirigidos a los sordos. Por lo tanto, debe considerarse que las personas sordas que actualmente asisten a la ES aportan el legado de las prácticas pedagógicas que se sometieron a la educación básica, así como el capital cultural "transmitido". En este sentido,

\footnotetext{
${ }^{1}$ Universidade Federal de Santa Catarina (UFSC), Florianópolis - SC - Brasil. Doutoranda no Programa de PósGraduação em Linguística. Docente de Educação Especial do Colégio de Aplicação da UFSC. CED/UFSC. ORCID: https://orcid.org/0000-0001-8808-8606. E-mail: alineolin@yahoo.com.br

${ }^{2}$ Universidade Federal de Santa Catarina (UFSC), Florianópolis - SC - Brasil. Professora Associada no Curso de Fonoaudiologia e no Programa de Pós-graduação em Linguística. Doutorado em Linguística (UNICAMP). ORCID: https://orcid.org/0000-0002-9508-9866. E-mail:anaposantana@hotmail.com
} 
el objetivo de este estudio es comprender las condiciones de alfabetización de estudiantes sordos de la educación superior, relacionándolas con su inserción en la cultura escrita y las implicaciones para su permanencia en la universidad. Es una investigación cualitativa, siendo un estudio de caso de dos estudiantes graduados sordos. La lectura y escritura de géneros académicos generalmente se realiza en la universidad, porque la producción de estos géneros es inherente a la institución universitaria. Desde una perspectiva bakhtiniana, se discute la apropiación de géneros secundarios en la esfera del conocimiento en el que están constituidos: en la universidad. Se concluye que el hecho de que los sujetos no dominaran el idioma portugués en modo escrito (L2) no interfirió con la permanencia y el éxito académico de las personas sordas que participaron de esta investigación cuando se sumergieron en un contexto educativo universitario en el que se prioriza la Libras. Esta falta de dominio no impidió el ingreso a la educación superior, a nivel de pregrado y posgrado, y presentó un rendimiento académico compatible con la complejidad requerida en dichos niveles de educación, aunque las prácticas de alfabetización de los sujetos y la transmisión del capital cultural ha demostrado ser un diferencial en este proceso para el dominio de L2.

PALABRAS CLAVE: Sordo. Estudiantes universitarios. Alfabetización. Capital cultural. Permanencia.

ABSTRACT: Access to Higher Education (ES) in Brazil expanded considering changes in inclusive policies, as well as those specifically targeted at the deaf. Thus, it must be considered that deaf people who currently attend the ES bring the legacy of the pedagogical practices that were submitted to basic education, as well as the "transmitted" cultural capital. In this sense, the objective of this study is to understand the deaf university's literacy conditions, relating them to their insertion in the written culture and the implications for their permanence in the university. It is a qualitative research, being a case study of two deaf graduate students. Reading and writing of academic genres is usually done at the university, because the production of these genres is inherent to the university institution. From a Bakhtinian perspective, the appropriation of secondary genres in the sphere of knowledge in which they are constituted is discussed: at the university. It is concluded that the fact that the subjects did not proficiently master the Portuguese language in written mode (L2) did not interfere with the permanence and academic success of deaf people involved in this research when immersed in a university educational context in which Libras is prioritized. This lack of mastery did not prevent entry into higher education, at undergraduate and later postgraduate level, and from presenting academic performance compatible with the complexity required at such levels of education, although the subjects' literacy practices and transmission of cultural capital have proved to be a differential in this process for the domain of $L 2$.

KEYWORDS: Deaf college students. Literacy. Cultural capital. Permanence.

\section{Introdução}

O acesso à Educação Superior (ES) no Brasil vem se expandindo tendo em vista as modificações ocorridas com as políticas educacionais inclusivas, bem como às voltadas especificamente para os surdos. No que se refere ao campo da surdez, o censo de 2015 aponta 
que entre os anos de 2010 e 2015, o número de estudantes com deficiência auditiva aumentou $20,76 \%$ e de estudantes surdos em 35\% (ESDRAS; GALASSO, 2017).

Cabe ressaltar que o acesso à instituição superior não garante condições de permanência na universidade e tampouco oferece garantia de práticas de ensino e aprendizagem efetivas para o estudante surdo. Aliás, observa-se, muitas vezes, certo desconforto diante desses estudantes, tanto por parte da instituição como de profissionais, exigindo assim, a compreensão dessa dificuldade e a busca pela identificação de modos de enfrentá-la (DAROQUE; PADILHA, 2012).

Neste contexto, há de se considerar que os surdos que, atualmente, frequentam a ES, trazem o legado das práticas pedagógicas nas quais foram submetidos durante a Educação Básica. Conforme Daroque e Padilha (2012), o Oralismo e a Comunicação Total buscavam o apagamento da surdez, os surdos viviam anos de escolarização submetidos aos métodos tradicionais de alfabetização, ficando à disposição de modelos que não eram apropriados sequer para os ouvintes.

Apenas a partir da década de 1990, o Bilinguismo surge como abordagem educacional para surdos no Brasil. Perlin (2006) ressalta que esse movimento deu-se a partir de discussões de linguistas em relação à língua de sinais, originada pela insatisfação do surdo diante da proibição do uso da língua de sinais e a mobilização das comunidades surdas. Essa mobilização ganhou legitimidade a partir do momento em que a Língua Brasileira de Sinais - Libras - ganha status, por meio da Lei n. 10.436/2002 (BRASIL, 2002). A partir da perspectiva bilíngue, o português é compreendido como uma segunda língua para o surdo brasileiro, sendo a Libras, que por sua vez dará o arcabouço para a aprendizagem da segunda, pois preenche as funções que a linguagem falada tem para os ouvintes (PEREIRA, 2009).

Com a oficialização da Libras, desdobramentos importantes para educação de surdos começam a acontecer no país, como a publicação do Decreto n. 5.626/2005, que regulamenta tal lei e fundamenta a Educação Bilíngue para os surdos (BRASIL, 2005) e a publicação do Estatuto da Pessoa com Deficiência - Lei Brasileira de Inclusão n. 13.146/2015, que corrobora com a perspectiva da Educação Inclusiva e da Educação Bilíngue para os surdos (BRASIL, 2015).

O Bilinguismo inaugura, assim, um novo debate em favor da língua de sinais, da cultura surda e ainda da possibilidade de alfabetização e letramento dos surdos que, em sua maioria, foram excluídos por um sistema educacional que, até então, não considerava a diversidade linguística e cultural. 
Ressalte-se aqui, que a educação oralista que se constituiu historicamente, até promoveu o avanço da escolaridade dos surdos, mas não se pode dizer que os surdos foram efetivamente alfabetizados e imersos em práticas letradas. Eram estudantes copistas em sua grande maioria que passavam de ano, mas não dominavam o português escrito (SANTANA; CARNEIRO 2012).

Pereira (2009) analisa que o processo de aquisição da escrita como segunda língua pelos surdos, apresenta resultados insatisfatórios. A maior parte dos surdos têm dificuldades, pois falta uma língua constituída para que possam construir a escrita. Quando entram na escola, a maioria das crianças surdas ainda não domina uma língua com base na qual possa dar condições de iniciar a aprendizagem da leitura e escrita, ao contrário dos ouvintes, que já ingressam dominando a língua materna na modalidade oral.

É fundamental considerar, assim, que a escrita da Língua Portuguesa para o surdo é a escrita de uma segunda língua. Ressalte-se ainda a diferença de modalidades entre essas línguas, uma vez que o português é de modalidade oral-auditiva enquanto a Libras é espaço-visual. O português como segunda língua para os surdos apresentará características de aquisição observados em processos de aquisição de outras línguas, ou seja, observa-se uma variação individual tanto no êxito, quanto no processo, assim como nas estratégias e objetivos usados pelos próprios sujeitos (QUADROS, 2006).

Diante desses pressupostos, o objetivo deste estudo, é compreender as condições de letramento do surdo universitário, relacionando-as a sua inserção na cultura escrita e as implicações para a permanência na universidade, a partir de estudo de casos de dois estudantes surdos universitários da pós-graduação.

\section{Letramento, surdez e Educação Superior}

Para Rojo (2004), o conceito de Letramento não se limita a apropriação e conhecimento do alfabeto, mas sim, se refere ao processo de apropriação das práticas sociais de leitura e escrita, bem como das capacidades envolvidas nessas práticas, como a decodificação, compreensão, apreciação, interpretação, interação. Assim, o fato da pessoa ser alfabetizada, ter aprendido a ler e a escrever, não garante a incorporação e envolvimento nas práticas sociais de leitura e escrita, por isso, as pessoas podem se sair de modo diferente de acordo com cada esfera de atividade humana.

Bakhtin (2015[1979]) a respeito dos conceitos de esfera de atividade ou de circulação de discursos e o conceito de gêneros discursivos, pontua que na vida cotidiana, circulamos por 
diferentes esferas de atividades (doméstica e familiar, do trabalho, escolar, acadêmica, jornalística, publicitária, burocrática, religiosa, artística e etc), e em diferentes posições, como produtores ou receptores/consumidores de discursos, em gêneros variados, mídias diversas e em culturas também diferentes.

Assim, de acordo com o autor, cada uma das esferas de atividade humana, atua também como esfera de circulação de discursos, bem como de utilização da língua. Cada esfera de utilização da língua, elabora seus tipos de enunciados, o que denomina de gêneros do discurso. O gênero ou o enunciado reflete as especificidades e as finalidades de cada esfera.

$\mathrm{Na}$ universidade, a expectativa por parte dos docentes é de que os estudantes tenham domínio da língua na modalidade escrita, que saibam ler e escrever o português de forma proficiente em diversos gêneros discursivos que aí circulam. Na esfera acadêmica, inserem-se práticas sociais que valorizam e legitimam o domínio de determinadas práticas de leitura e de escrita.

Desta forma, espera-se que os estudantes, ao ingressarem na Educação Superior, já dominem o Letramento Acadêmico (FISCHER, 2007). Por Letramento Acadêmico compreende-se o domínio de gêneros discursivos secundários vivenciados no contexto universitário, tais como artigos, resenhas, monografias, relatórios, trabalhos de conclusão de cursos, dentre outros (SANTANA; STOLSKY, 2014). Há de se considerar ainda toda uma prática interativa que ocorre nesse contexto, como a relação entre professor-aluno-colegas, as dinâmicas estabelecidas em cada aula, como a apresentação de um trabalho em slides, a utilização de computadores, ferramentas digitais, entre outros) etc (FISCHER, 2007).

É importante ressaltar que muitos universitários ainda não conseguem se apropriar do Letramento Acadêmico. Na Educação Superior há 4\% de universitários considerados analfabetos funcionais (nível rudimentar), enquanto os que são considerados funcionalmente alfabetizados, somam 96\% (32\% no nível elementar, 42\% no nível intermediário e 22\% proficiente (INAF, 2016).

Se essa condição é relacionada aos ouvintes, para os surdos, possivelmente o domínio de Letramento Acadêmico ainda é mais distante. Isso decorre de uma vivência no contexto educacinal, muitas vezes, limitada à pouca prática de letramento ou ainda a práticas escolarizadas tão somente (cópia, ditado, leitura de livros didáticos).

Sobre a linguagem escrita dos surdos, a literatura já vem apontando características presentes e dificuldades no domínio da segunda língua, tais como: restrições de vocabulário e construções frasais estereotipadas sem elementos de ligação, dificuldades na conjugação verbal, no uso de gêneros e concordância verbal e nominal, dentre outros. Embora os surdos consigam 
apreender o sentido das palavras, ainda encontram dificuldades em usar a língua escrita de modo efetivo e explorar os textos de forma significativa (GUARINELLO et al., 2009).

Essas dificuldades decorrem, principalmente, devido às dificuldades ocasionadas pela aquisição de uma língua (tanto oral - pelas questões auditivas - quanto a língua de sinais - pela falta de interações na língua). Nesse caso, muitos surdos possuem um acesso precário à cultura escrita considerando a falta de uma língua para mediar a escrita (SANTANA, 2013).

A questão que se coloca aqui é: "os surdos" seriam/fazem parte de um grupo homogênero? De que forma eles estão inseridos na cultura escrita? Quais as práticas de letramento vivenciadas por eles? Considere-se aqui, que a família do surdo é uma família constituída por ouvinte (em 90\% dos casos) e que os pais não dominam (geralmente) a Libras. Há, nesse sentido, possivelmente, poucas práticas de letramento mediadas pela língua de sinais no contexto familiar.

O papel do contexto familiar na apropriação da linguagem escrita já vem sendo descrito na literatura há algum tempo (LAHIRE, 1997). Os estudos em Sociologia da Educação (BOURDIEU, 1998; 2001; 2002; 2011; BOURDIEU; PASSERON, 2014[1964]) demonstram a importância da família em termos de transmissão cultural. Levando-se em conta que a cultura escrita pode ser considerada um "capital cultural" "transmitido" entre gerações, as crianças surdas, em sua maioria, não têm como ter acesso a esse capital (BOURDIEU, 1998). A falta de domínio da língua de sinais pelos pais gera um "impedimento" na interação, que por consequência, interfere na transmissão do capital cultural, sobretudo no que discute-se nesse trabalho: a cultura escrita.

Conforme Lahire (1997), a familiaridade da criança com a leitura pode conduzi-la ao sucesso escolar. Quando a criança tem acesso a histórias lidas por seus pais, na relação afetiva, ela capitaliza estruturas textuais que serão reinvestidas em suas leituras e produções escritas. Neste contexto, para a criança, o texto escrito, o livro, faz parte do seu cotidiano enquanto recebe afeto de seus pais. Assim, há de se considerar também o quanto esses aspectos estiveram e/ou estão presentes no contexto familiar do sujeito e de que forma se materializa e/ou se constitui naquele contexto. Assim, entende-se que em posse de um determinado capital cultural que se predispôs a valorizar e a incentivar o conhecimento escolar, entre eles a escrita, seriam importantes elementos para o alcance do sucesso acadêmico. Ou seja, sujeitos com maior acesso aos bens culturais seriam os que teriam maiores chances de obter um bom desempenho escolar (SETTON, 2005).

Isso não trata-se apenas da presença ou não de livros em casa, mas sim, se a experiência é vivida de forma positiva ou negativa pela criança. Por exemplo, os livros podem ser 
respeitados demais, de modo que a criança não pode explorá-los sozinha; ou mesmo disponibilizados como um brinquedo, tendo elas que aprender a manejá-los de modo solitário. Observar os pais lendo jornais, livros, revistas, contribui para que a criança atribua naturalidade a tais atos, assim como observar os pais lerem e escreverem sem dificuldades (LAHIRE, 1997).

A participação da criança em práticas de escrita cotidianas nas formas de organização doméstica, como uma lista de compras, lembretes, listas de coisas para fazer, receitas copiadas, livros de contas, entre outros, contribuem também para uma gestão mais racional e menos imediata das atividades familiares, o que ajuda na construção do sentido que a criança dará ao texto escrito no contexto escolar.

Outro aspecto a ser considerado são as condições e disposições econômicas apresentadas pela família para a existência e desenvolvimento de uma cultura escrita. A ordem moral doméstica também é um fator determinante, por meio de uma presença constante, de um apoio moral ou afetivo estável, a família consegue acompanhar a escolaridade da criança (LAHIRE, 1997).

Setton (2005) aponta que Lahire (1997) alerta para as possibilidades e condições de utilização e presença um capital cultural. A escrita, por exemplo, só ganhará sentido se tiver em condições que tornem possível sua a "transmissão". Para esse autor, não é suficiente a criança estar cercada de objetos ou circular em ambientes estimulantes do ponto de vista educacional, mas é necessário estar atento para as modalidades efetivas de "transmissão" dessas disposições culturais. A escola, por outro lado, poderia ser a "transmissora desse capital cultural", mas também estava omissa pela falta de uma língua em comum.

Nesse sentido, uma questão importante é a reflexão sobre a forma com que esse capital cultural tem sido transmitido de pais ouvintes para filhos surdos, principalmente quando não há uma uma língua em comum.

Sobre as práticas de leitura de livro em língua de sinais, Santana (2016), afirma que se $90 \%$ dos surdos são filhos de pais ouvintes, o gosto pela leitura em língua de sinais não pode ser "herdado" em suas práticas sociais familiares. A família ouvinte não seria possuidora de um bem cultural a ser transmitido pelos familiares dos surdos. A autora ainda afirma que, não há transmissão de capital cultural familiar entre pais ouvintes e filhos surdos já que, muitos surdos, apenas na universidade, entram em contato com os livros editados em língua de sinais por meio de disciplinas específicas voltadas às discussões da "Cultura Surda". Desta forma, para Santana (2016), a transmissão e a circulação desses livros entre ouvintes (pais e professores) e surdos seria precária.

Levar em conta todas essas questões sobre o letramento dos surdos universitários, 
implica considerar que as práticas de letramento apresentadas por esses sujeitos estão entrelaçadas a vários fatores que podem ser determinantes para seu sucesso acadêmico, sendo os principais, às condições de apropriação da primeira língua, seja ela na modalidade oral ou viso-gestual e as práticas de letramento e a sua inserção na cultura escrita.

\section{Apresentando os dados da pesquisa}

Os dados apresentados neste estudo referem-se ao estudo de caso de dois estudantes de uma universidade do sul país, alunos da pós-graduação, que apresentam perda auditiva de severa a profunda bilateralmente. Os procedimentos da pesquisa envolveram os seguintes aspectos:

i) Entrevista com a finalidade de analisar a história educacional dos sujeitos surdos envolvidos na pesquisa, bem como as implicações para suas práticas de leitura e escrita, buscando detalhamentos acerca de suas práticas e eventos de letramento na segunda língua (Língua Portuguesa), tanto as anteriores como as atuais. ii) Produção Escrita do surdo - com a finalidade de compreender melhor suas dificuldades.

Neste estudo, utilizam-se nomes fictícios para referência aos estudantes, João e Maria, respectivamente. Os dados coletados da entrevista foram filmados e transcritos para análise. Os sujeitos também responderam questionários por escrito, com questões abertas e fechadas. As entrevistas foram analisadas a partir de uma abordagem enunciativa-discursiva assentada em Bakhtin $(2015[1979])^{3}$.

A seguir descreve-se brevemente sobre os estudantes participantes dessa pesquisa.

\section{Conhecendo João}

João é surdo (apresenta perda auditiva profunda bilateral), à época da pesquisa possuía 35 anos (ano de 2016). Sua vida universitária iniciou em 2007, concluindo a graduação de Letras-Libras à distância. Atualmente, faz disciplina como aluno especial do mestrando e é professor de Libras da Educação Básica. Considera-se bilíngue, pois usa para suas trocas interativas: a Libras como primeira língua e o português (na modalidade escrita) como segunda língua.

${ }^{3} \mathrm{O}$ presente estudo foi iniciado somente após submissão e aprovação do projeto no Comitê de Ética e Pesquisa, por conseguinte, aceite e assinatura do Termo de Consentimento Livre e Esclarecido e Termo de Consentimento de gravação audiovisual por parte dos sujeitos de pesquisa. Número do parecer: 05845412.1.0000.0121. 
Ele usava aparelho auditivo (AASI) com pouca frequência na infância e adolescência, pois achava o som ruim, não conseguia entender a fala das pessoas ou diferenciar os sons ambientais. Logo, achava desconfortável, então, ele parou de usar. João frequentou terapia fonoaudiológica desde o primeiro ano de idade até os dezessete anos. Os anos na Fonoaudiologia não trouxeram resultados segundo ele, mesmo porque, quando teve acesso à Libras, não teve mais interesse de falar. Atualmente, não faz uso da linguagem oral para se comunicar.

João cresceu em uma família de ouvintes composta por cinco pessoas incluindo ele (mãe, pai, irmão e irmã). Sua mãe trabalhava como supervisora de creches. João não sabe sobre sua escolaridade, pois a mãe veio a falecer quando era muito jovem. Seu pai é dono de uma loja de pneus e estudou até o $4^{\circ}$ ano do Ensino Fundamental. Seu irmão atualmente trabalha com o pai na loja e estudou pouco. João não lembra exatamente até qual ano seu irmão estudou. Sua irmã possui pós-graduação e é professora municipal e coordenadora pedagógica em uma faculdade.

João estudou em escolas de ouvintes. Nessa época, não sabia Libras e tampouco tinha intérprete de língua de sinais em sala de aula. Ele tinha bastante dificuldade para aprender os conteúdos escolares que lhe eram repassados por meio da oralidade. João não teve acesso em nenhum momento de sua trajetória educacional ao Atendimento Especializado na escola.

Quanto à escrita, João aprendeu a fazer cópias, mas não sabia efetivamente ler e escrever. Ele mencionou que conseguia boas notas nas provas porque "colava" e os professores o passavam de ano. Mesmo assim, teve algumas reprovações durante o percurso escolar e, por isso, abandonou a escola no Ensino Fundamental. João voltou a estudar aos 17 anos no Centro de Educação de Jovens e Adultos e, dessa forma, concluindo o Ensino Fundamental e Ensino Médio.

Sobre os livros que possuíam em casa, João não soube especificar sobre a presença deles durante sua infância e adolescência. Embore recorde-se que quando mudaram-se de casa, na qual viveu por pouco tempo, tinha alguns livros guardados no armário, mas não sabe do que se tratavam. Ele também não tem lembranças de seus pais lendo, só de sua irmã mais velha. Era apenas ela quem contava histórias a ele e ao irmão quando criança, tais como "Chapeuzinho Vermelho", "Os três porquinhos". João teve o primeiro contato com a Libras aos 14 anos, na associação de surdos, momento em que sua família também se interessou em aprender a língua. Depois que aprendeu Libras sua vida melhorou: "as coisas ficaram mais claras e com significado". 
Após a conclusão da EJA, João prestou vestibular para Letras-Libras na instituição por duas vezes. Apesar de ter intérprete para realizar a prova, somente na segunda tentativa foi aprovado. Também prestou vestibular duas vezes para Pedagogia em uma instituição particular, sem intérprete, e só na segunda vez conseguiu aprovação.

No curso de Pedagogia, os professores só oralizavam e o intérprete não possuía muita proficiência em Libras. As metodologias de ensino eram para ouvintes e as dificuldades de comunicação continuavam. Dessa forma, no segundo ano, João decidiu desistir do curso.

Já no curso de Letras-Libras, os professores, surdos e ouvintes, conheciam a cultura surda. A metodologia das aulas era própria para surdos, tinha intérprete e os materiais didáticos eram bilíngues. Alguns professores cobravam mais a Libras e outros cobravam mais o português escrito. João apresentava ainda algumas dificuldades com o português escrito, mas contava com os intérpretes para auxiliá-lo na leitura e escrita dos textos. Na disciplina que cursava no mestrado, João contava com intérprete, mas não havia materiais didáticos bilíngues, os textos eram todos em português e mais complexos. Quando tinha dificuldades para a leitura ou produções escritas, mencionava que iria agendar horário extra com professores e intérpretes.

$\mathrm{Na}$ época da coleta de dados, João morava sozinho, tinha vários livros em casa, principalmente livros técnicos sobre Libras e Literatura. Os livros são guardados em armários com gavetas em seu quarto. Quanto aos hábitos de leitura, lê diariamente textos técnicos do trabalho e do mestrado, bem como jornais, revistas, artigos e notícias da internet.

Os gêneros primários, como solicitação de uma informação a alguém por meio da escrita, bilhete, bate-papo na internet são mais fáceis para João. Quanto à escrita de gêneros secundários, como os exigidos na universidade, o estudante menciona que, às vezes, encontra dificuldade, então, recorre ao apoio de estudantes ouvintes, professores ou intérpretes.

\section{Leitura e escrita de João}

João apresenta dificuldades com relação à leitura. Há vários gêneros que ainda não domina, mesmo os gêneros primários como notícia e cartazes. Ele precisa de leitura e releitura, e até mesmo auxílio de um mediador, para que consiga entender o sentido e o objetivo do gênero. João decodifica visualmente as informações explícitas do texto, mas quando há necessidade de inferências, a dificuldade fica mais acentuada, sobretudo, por não conseguir identificar os elementos implícitos ao texto, o que fragiliza a sua compreensão da leitura.

Sobre a escrita, para ilustrar, apresentamos abaixo uma resenha escrita e com o tema escolhido por ele sobre: "Bilinguismo para os Surdos". 
Quadro 1 - Escrita de João

\begin{abstract}
"Os surdos implantes cocleares precisam aprender L1, L2 e fonoaudiologia sabe do contexto ler o texto, revista, livro e jornal também fala comunicação pessoal, o medico influência do proibido em libras com a família o negativo comunicação mas eles falham por causa o medico e mito, implantes cocleares aparelho, depende ouvinte meio consegui comunicação, então surdo profundo e dificuldade. Precisam os surdos e implantes cocleares igualdade estuda aprender em libras na sala da bilíngue. Anteriormente o bebê surdo ou implantes cocleares aprende do rápido L1 e L2, adulto atrasado não consegui de linguagem fraco L2, consegui só em libras, a família precisa em libras comunicação com os surdos, ela não quere em libras do não comunicação problema acontece confusão do gesto."
\end{abstract}

Fonte: Elaborado pelas autoras

\title{
Relatos de João sobre seu acesso à escola e suas práticas de letramento
}

\section{O contexto educacional}

Não tinha intérprete, os professores não estavam nem aí pra mim, não se preocupavam comigo. Na leitura, tinha dificuldades de entender, tive um bloqueio na comunicação. Os professores diziam: "vai ler tudo para prova!". Eu ficava assustado, preocupado. Ai eu lia, pensava, imaginava, mas não entendia o significado da palavra. Era horrivel.

[...] minha família me colocou em uma escola para ouvintes, era muito dificil, não era fácil, não tinha intérprete, então eu sentava ao lado dos ouvintes para copiar deles, os professores me passavam de ano, às vezes me aceitavam... Às vezes eu era aprovado, às vezes reprovado. [...] os professores me ensinavam português...não era Libras, era comunicação total, a Libras era confusa, o português era difícil, eu não entendia, por exemplo a palavra "BOLA" eu entendia, "MESA", "CADEIRA", as coisas, enfim...mas os verbos eu não sabia, eu não entendia, não ficava claro, os professores me explicavam, mas eu não entendia...eu não entendia os verbos...eu pensava, pensava ...[..]

\section{$O$ contexto universitário}

No começo era dificil, os estudos eram muito pesados, eram muitas disciplinas e tudo era muito rápido, minha cabeça estava sempre cheia...depois que eu terminei ficou mais leve, mais fácil... [...]No TCC podia escolher o português e as regras da ABNT, ou também podia fazer a filmagem em Libras. Eu escolhi português porque a filmagem em Libras é muito demorada, é dificil, tem que editar, dá muito trabalho, ai eu tinha que aprender fazer isso e eu tinha que entregar rápido, já estava preocupado, então eu fiz em português, escrevi, mas depois eu dei para outra pessoa revisar, organizar o meu português, porque o meu conhecimento em português não é profundo, então eu paguei outra pessoa para organizar o texto só. 


\section{Sobre as práticas de leitura}

Bem pouquinho [referindo-se aos seus hábitos de leitura], não tenho tempo, estou sempre ocupado, muitas coisas, eu costumo ver materiais em Libras, ai eu assisto.......] Hoje na minha casa eu tenho uma pilha de livros, tem livro em Libras, de contação de histórias, vários...

Não tenho, é normal...eu faço assim: eu escrevo e sempre peço para algum ouvinte arrumar...no bate-papo é fácil a comunicação escrita, mas às vezes preciso de um português mais profundo, ai depende da situação.

\section{Conhecendo Maria}

Maria é surda (tem perda auditiva severa à orelha direita e profunda à esquerda), formada em Letras-Libras e em Pedagogia em uma instituição particular. Atualmente, é mestranda e professora de Libras da Educação Básica. Sua vida universitária iniciou no ano de 2006. Na época desta pesquisa (ano 2016), tinha 28 anos. Ela considera-se bilíngue, pois usa para suas trocas interativas a Libras como primeira língua e português escrito como segunda língua.

Maria frequentou terapia fonoaudiológica desde os 6 anos até os 14 anos de idade, período em que usou prótese auditiva. Embora saiba oralizar, opta pela Libras. Atualmente, é casada com um surdo, que também é bilíngue.

Maria cresceu em uma família de ouvintes, composta por cinco pessoas, incluindo ela, pai, mãe e dois irmãos. A mãe é professora, o pai empresário, um dos irmão é administrador de empresas e o outro é estudante do Ensino Médio. Sua família não sabe Libras, portanto, ela se comunica com eles por meio da oralidade. Apesar disso, Maria considera sua interação com a família fácil, pois já conhece o jeito de falar deles. Contudo, menciona que com pessoas estranhas, a comunicação oral é difícil. Maria tem lembranças de muitos livros em sua casa, estes estavam sempre à disposição, eram guardados em armários no quarto e também ficavam expostos sobre as mesas. A leitura era, assim, muito valorizada. Os livros eram lidos para ela, por ela e pela família. A mãe lia livros de romance e técnicos, revistas; o pai lia jornal.

$\mathrm{Na}$ época da pesquisa, além das leituras acadêmicas, a estudante também lia romances e notícias na internet. Menciona que os textos acadêmicos são mais difíceis, pois precisava pesquisar o significado das palavras na internet ou em dicionários. Ela sente a necessidade de um conhecimento mais profundo da Língua Portuguesa escrita, principalmente relacionado ao significado das palavras. Quantos à escrita de textos mais complexos, como os exigidos na universidade, Maria menciona que, às vezes, encontra dificuldade, então recorre aos dicionários ou pede apoio aos professores ou aos intérpretes. 
Maria estudou em escolas de ouvintes, não sabia Libras e tampouco tinha intérprete de Língua de Sinais em sala de aula. Ela frequentava sala de recursos no contraturno com outros alunos surdos, onde recebia reforço escolar. Tinha muita dificuldade para aprender os conteúdos escolares que lhe eram repassados por meio da oralidade. Quanto à escrita, aprendeu a fazer cópias, mas não sabia efetivamente ler e escrever. Sua família lhe ajudava muito nas tarefas escolares e era muito exigente com Maria. Ela nunca reprovou, não porque não tinha dificuldades, mas porque os professores a passavam de ano considerando seu esforço.

Maria teve o primeiro contato com a Libras aos 17 anos, na associação de surdos de sua cidade. Sua família não aprendeu Libras e até hoje utiliza a oralização e gestos para a comunicação.

A estudante fez faculdade de Pedagogia em uma instituição que não tinha intérprete, esforçou-se muito para concluí-la e teve apoio da família para a realização dos trabalhos acadêmicos, devido às dificuldades com a leitura e a escrita, bem como de acompanhar as explicações dos professores em sala de aula. Por causa disso, ela teve duas reprovações na faculdade, em disciplinas que tinham muitos textos para leitura. Após essa graduação, formouse em Letras-Libras, onde não apresentou dificuldades, pois a metodologia era apropriada para surdos, tinha intérprete e contava com materiais didáticos bilíngues. Neste contexto, sentia-se muito acolhida, tudo passou a ter mais significado e a aprendizagem lhe era mais significativa.

No mestrado, Maria contou com intérprete, mas não havia materiais didáticos bilíngues. Os textos estavam todos escritos em português e eram mais complexos Quando Maria tem dificuldades para a leitura dos textos ou produções escritas, ela ressalta que agenda horário extra com professores e intérpretes.

\section{Leitura e escrita de Maria}

Maria demonstrou compreensão leitora dos textos, gêneros primários e secundários, apresentando respostas completas e coerentes com as temáticas dos mesmos, identificando os elementos textuais explícitos e implícitos, bem como realizando inferências.

Sobre a escrita, para ilustrar, apresentamos abaixo uma resenha escrita e com o tema escolhido por ela sobre: "Bilinguismo para os Surdos".

\section{Quadro 2 - Escrita de Maria}

\footnotetext{
"As escolas aceitam o ingresso do aluno surdo, mas não garantem sua permanência e a qualidade na mediação. A escola está assumindo um papel de escola inclusiva à
} 
ascensão social, mas estão se equivocando e transformando-se num espaço de exclusão, não somente com aqueles que não se enquadram no padrão imaginário do aluno dito "normal", ou seja, as instituições por conta da lei estão se transformando em um depósito de todos aqueles que por uma razão ou outra não se enquadram no sistema escolar. Um dos maiores problemas que vem acontecendo é que nas escolas para ouvintes, que recebem alunos surdos dizendo ser inclusivas, o professor não domina a língua de sinais e o aluno acaba sendo deixado de lado. Eles recebem fragmentos do trabalho do professor com o uso de sinais isolados que não caracterizam a comunicação, adotando o português como única língua, sem se preocupar com a língua de sinais, que é a primeira dos surdos. Assim, seja positivamente á luta pela educação bilíngue á favor de comunidade surda e os professores surdos de Libras."

Fonte: Elaborado pelas autoras

\section{O contexto educacional}

minha escrita era ruim, minha mãe cobrava, sábado e domingo às vezes minha mãe me chamava para ler, palavras, escrever... Em muitas coisas minha mãe me ajudou, a escola também ajudou na comunicação total na sala do AEE, ajudava nos trabalhos da sala de aula normal. Eu cansava, estudava de manhã e de tarde e também à noite. Três vezes na semana eu ia na fonoaudióloga particular aprender a falar certo, treinava...ela passava batom e eu beijava a mão, [...] fazia movimento com a boca e eu não aprendia nada, parecia desanimada...

Quando eu era criança, quando eu estava na primeira série, eu lembro de uma professora muito ruim, da inclusão e não tinha intérprete, a professora batia em mim, porque eu não entendia nada, e eu me sentia muito mal de ver aquilo...Depois passou o tempo, quando eu era adolescente, perto de fazer o vestibular, eu vi a mesma professora batendo em um aluno cego...então eu pensei "eu vou escolher Pedagogia", porque eu quero trabalhar com criança surda e eu não quero bater, porque eu fiquei triste com aquilo, então eu pensei que queria ser professora de Libras, por isso escolhi Pedagogia e depois eu pude fazer Letras-Libras.

\section{O contexto universitário}

[...] Na Pedagogia, então o surdo sempre junto comigo, eu sentia que os ouvintes não aceitavam fazer trabalhos em grupo comigo, achavam que surdo não sabe apresentar, surdo não sabe preparar projeto de ensino, didática, então nós dois surdos juntos. No Letras-Libras mudou muito, porque tinha muitos surdos, eu aprendia muito, pegava tudo muito rápido, materiais, professores, informações...eu sentia que aprendia de verdade...Na Pedagogia era pouca coisa, muito fraco, Letras-Libras era rápido.

\section{Sobre as práticas de leitura e escrita}

O meu processo de letramento...eu consegui aprender, desenvolver, porque família ajudou muito, também porque a escola, o AEE ajudou muito, a fono 
também me ajudou com as palavras, os significados, me ajudava...eu consegui me desenvolver, até hoje palavras também. [...] Minha mãe lê muitos livros, meu pai lê mais jornais, também na internet, faz pesquisas...o meu irmão não...eu lia pouco, agora comecei a ler mais.

Alguns textos como romances são fáceis de ler, outros livros pesados de teoria são mais dificeis, depende do texto. [...] Eu gosto muito de livros de romance, leio, também faço relação com filmes, eu gosto... outros livros do mestrado tem por exemplo língua de sinais mundiais, muita teoria, também inglês, palavras dificeis que eu não conheço o significado, mas a professora explica o significado, então quando eu tenho dificuldade eu procuro os professores, pesquiso no google, na internet, nos livros, então eu entendo e fica clara a palavra, senão não tem como entender...

Eu compro revista uma vez na semana, dai eu leio bastante, todos os dias não, depende do tempo, por exemplo quando viajo leio muito. Sábado e domingo, quando não tenho nada pra fazer eu leio revistas também, mas agora eu leio pouco revistas, porque eu leio muitos textos para minha pesquisa. Veja, Interessante...também Época... Só fotos eu vejo [...] gosto de romance, narrativas, por exemplo livro de Deus, conselho [...] Tenho materiais, livros do mestrado em Libras, livros sobre explicação da Libras, da Cultura, Identidade, coisas do meu estudo sobre Libras, mas também tenho alguns livros de narrativas religiosas, mas mais sobre Libras. [...] Eu guardo no quarto de escritório, minha mesa é cheia de livros!

Eu leio em casa e quando viajo. $N a$ BU (Biblioteca Universitária) é dificil, porque não consigo focar na leitura, é muita informação visual.

[sobre livro que gosta/não gosta de ler] É dificil...romance, o nome eu não lembro...eu lembro tem um, o nome..."Amanhecer..." começa assim...romance entre um homem e uma mulher, igual o film [...] Livro que eu não gosto, nunca...porque eu sei que tenho que ler, eu pego pra ler, é bom...mas são os livros, textos do mestrado, de umas disciplinas pesadas...

Meu pai, minha mãe, se tem informação nova eles me mostram pra me ajudar, no jornal, se aconteceu alguma coisa em São Paulo eu não ligo, mas se meu pai me avisa aí eu me importo, eu foco.[...] No passado a família incentivava a leitura, era muito importante, hoje não, moro longe da minha família, meu marido não liga pra leitura, não gosta de ler, só jornal, mas eu busco muita leitura, ele que não gosta.

\section{Discussão}

A partir dos relatos de João observa-se que, com relação ao capital cultural transmitido pela família (LAHIRE, 1997) apesar dele ter convivido com alguns livros e materiais impressos em casa, estes não eram tão utilizados e valorizados pela família, com ele e por ele; exceto pela irmã que exerceu um papel fundamental no processo de formação educacional do irmão. João não costumava ver a família lendo, comprando livros, tampouco via os livros circularem no meio familiar. A respeito disso, é possível dizer que ele vivenciou esse distanciamento da 
cultura escrita tanto pela ausência de uma língua para mediar a transmissão cultural, quanto pelas poucas práticas de leitura e de escrita vivenciadas pela família.

A escrita de João mostrou-se coerente com a temática, trazendo informações importantes e problematizadoras sobre o assunto, porém com problemas de coesão, predominância da estrutura sintática da Libras, falta de conectivos, ausência ou uso indevido de artigos e pronomes, problemas de flexão verbal e nominal, o que é próprio a um falante/escritor de uma L2.

João referiu não ter apresentado dificuldades para a leitura e escrita dos gêneros propostos, tratando de forma naturalizada os possíveis "erros" apresentados na escrita do surdo, justificados pelo uso da Língua Portuguesa como segunda língua.

A trajetória escolar de João apresentou muitos obstáculos: histórico de reprovações, aprovações automáticas, dificuldades de aprendizagem, evasão escolar, falta de acesso à língua materna. Ou seja, uma história de fracasso escolar, onde suas necessidades não foram consideradas, com práticas que predominantemente com vistas à normalização do sujeito surdo, o que possivelmente interferiu no processo de aprendizagem da leitura e escrita (GOLDFELD, 2002; LODI, 2005; PERLIN, 2006; BOTELHO, 2016). Na época da pesquisa, apesar de ter se tornado professor, a leitura e a escrita em L2 estavam presentes como uma atividade de "obrigação" profissional. Dessa forma, observa-se que a escrita e leitura de João ainda refletem sua pouca apropriação de L2, trazendo resquícios de uma história de afastamento e sofrimento com o português escrito (LODI, 2005).

Nesse sentido, as práticas de leitura atuais de João, estabelecem-se mais por obrigação do que por prazer, embora "o livro" esteja sempre circulando em sua rotina: ele compra, ele empresta, ele lê. Mas quando depara-se com textos mais "maçantes" (o que se refere aos textos científicos que precisa ler para a disciplina do mestrado), recorre ao auxílio de intérpretes, mostrando que ainda não busca ler textos mais densos com autonomia.

A avaliação da leitura e escrita de João reflete, justamente, essa falta de domínio e de práticas letradas. Embora estejamos discutindo L2 e João ainda apresenta dificuldades com gêneros primários e secundários. Na leitura, ainda não consegue apreender efetivamente a função social dos gêneros avaliados já que possui dificuldades em identificar elementos implícitos nos textos e realizar inferências. Atribui-se, assim, essas lacunas ao processo de letramento do sujeito, ao capital cultural da escrita herdado da família, ou seja, com carência de práticas de letramento, bem como a falta de práticas de leitura e escrita atuais em L2 sem a mediação de intérpretes (LAHIRE, 1997). 
Com relação à Maria, observa-se que sua trajetória escolar, tal como João, foi marcada por muitos obstáculos, aprovações automáticas, dificuldades de aprendizagem, falta de acesso à língua materna, possivelmente devido a uma educação baseada no oralismo (BOTELHO, 2016). Contudo, diferente de João, Maria teve uma história marcada por práticas de leitura e escrita, pelo empenho familiar no auxílio a sua aprendizagem, e também da escola, com os recursos e serviços que dispunham na época, embora que pautados em concepções oralistas e integracionistas (LAHIRE, 1997).

O texto produzido por Maria cumpriu com a extensão combinada de duas laudas. Mostrou-se coerente com a temática, trazendo informações importantes e problematizadoras sobre o assunto, referenciadas corretamente com o artigo escolhido, bem como com sua própria opinião, apresentando estrutura compatível com a resenha crítica. A organização sintática da resenha respeitou a estrutura da Língua Portuguesa escrita, apresentando, em alguns momentos, falhas na flexão e concordâncias verbal e nominal. Maria referiu facilidade para a leitura e a escrita dos gêneros propostos nesta avaliação, o que pôde ser observado no processo avaliativo.

Com relação ao capital cultural transmitido pela família relacionado à leitura e à escrita, nota-se que as práticas de leitura e de escrita eram comuns no seu contexto familiar, assim como os demais materiais impressos de leitura e de escrita, que eram utilizados e valorizados pela família, com ela e por ela. Os livros e os materiais de leitura e de escrita circulavam e eram explorados livremente no contexto familiar. Desta forma, apesar do oralismo, ela participava de práticas de leitura e de escrita significativas que favoreceram sua constituição como leitora e escritora (LAHIRE, 1997).

$\mathrm{Na}$ época da pesquisa, a leitura e a escrita em L2 estavam presentes na vida de Maria, nas atividades profissionais e nas atividades de lazer, ou seja, a leitura era prazerosa. Maria foi submetida a muitas práticas de letramento no seio familiar, o que trouxe para a vida adulta, pois em sua casa, atualmente, o livro ganha espaço privilegiado, circulando e sendo explorado. Desafia-se a ler textos mais densos com autonomia, independente de serem livros acadêmicos ou romances.

A avaliação de leitura e de escrita de Maria corrobora com seu histórico de letramento, o qual foi favorável ao letramento em L2 que apresenta. Essa apropriação pode ser devida ao capital cultural da escrita "herdado da família", ou seja, com valoração da cultura escrita, pois Maria é capaz de realizar práticas de leitura e de escrita atuais em L2 sem a mediação de intérpretes. As dificuldades apresentadas por ela com relação aos gêneros primários e secundários são sutis, e estão mais relacionadas à escrita no que diz a ortografia e sintaxe, contudo não prejudica a compreensão por parte do interlocutor. 
Pode-se observar no discurso desses dois sujeitos, que na medida em que foram inseridos no universo da cultura surda, na língua de sinais (para ambos no final da adolescência) as informações e o conhecimento de modo geral, passaram a fazer mais sentido em suas vidas. Inclui-se aqui também, o entendimento da importância da língua de sinais para a escrita, melhorando a relação desses sujeitos com a leitura e a escrita (PEREIRA, 2009).

Vê-se assim que, historicamente, os surdos participaram de rotinas de exclusão. No contexto universitário, já em uma época mais atual, a partir da lei da Libras e das leis subsequentes que ratificam a importância da educação bilíngue, observa-se uma modificação de reconhecimento dessa língua. Contudo, não se pode deixar de ressaltar que o curso de Letras/Libras possui um diferencial para a formação do aluno a partir de aulas em Libras, pois nem sempre esse direito é garantido, como disse Maria, referindo-se à sua formação no curso de Pedagogia.

Importante também destacar que Setton (2005) afirma que existem fatores extraescolares - econômicos e culturais - que influenciam no desempenho e no aproveitamento do estudante. Há diferenças de várias ordens, sobretudo, de acesso aos bens da cultura, entre as famílias, que são responsáveis pela variação no comportamento e no rendimento referentes aos estudos. Dessa forma, as famílias transmitem aos seus filhos, mais por vias indiretas do que diretas, um determinado capital cultual e um ethos, valores implícitos e profundamente interiorizados, que contribuem para a definição das atitudes do sujeito diante do capital cultural e da instituição escolar. Assim, os sujeitos com maior acesso a uma cultura geral, apresentam condições diferenciadas para aquisição de uma cultura escolar.

Nota-se que, no contexto dos surdos, essas condições relacionam-se também por questões de ordem linguísticas, ou seja, as favorecidas pelo acesso ao bem cultural transmitido pelas trocas interativas por meio de sua primeira língua, a Libras, no caso dos surdos brasileiros.

\section{Considerações finais}

Este estudo procurou levantar questões sobre a surdez e o letramento do estudante surdo universitário. Sabe-se que as práticas pedagógicas oralistas propiciaram um afastamento do surdo da cultura escrita. Dessa forma, a preocupação em oralizar e alfabetizar, não permitia a constitução do surdo enquanto leitor e autor e sua inserção na cultura escrita. Tampouco houve a preocupação com uma prática de leitura de livros em língua de sinais (SANTANA, 2016).

Nos casos apresentados observou-se que a aquisição tardia da língua de sinais pelos surdos e, posteriormente, a ausência de intérpretes, tiveram como implicação a participação 
mais efetiva da família, apoiando nas tarefas escolares e acadêmicas. Ambos os sujeitos revelaram em seu discurso dificuldades em lidar com a escrita no percurso educacional. $\mathrm{O}$ percurso escolar vivenciado por eles, reflete as práticas em que foram submetidos, observandose atentando-se para a predominância da concepção oralista e da comunicação total. Visivelmente, essas práticas denunciam as suas dificuldades em lidar com o código escrito e fazer uso significativo da leitura e da escrita (GUARINELLO et al., 2009).

Nesse sentido, nota-se que o percurso educacional e clínico dos surdos foram marcados predominantemente por práticas oralistas, pela falta de uma língua constituída, língua de sinais ou oral, pela falta de acesso aos conteúdos escolares por meio de uma língua constituída, pela aquisição tardia da língua de sinais, pela falta de intérpretes de língua de sinais no contexto educacional e social de modo geral. Observa-se ou Considera-se também, que muitos foram os impeditivos para a aprendizagem da Língua Portuguesa de forma adequada, com métodos incompatíveis com a especificidade do sujeito surdo para o acesso às práticas de letramento. Contudo, percebe-se ou depreende-se que, o domínio da língua de sinais e a valorização dessa língua na Educação Superior, garantiram a permanência e o sucesso acadêmico dos sujeitos nesse contexto, independente das dificuldades com a leitura e a escrita.

Nos dois casos apresentados, evidencia-se que os dois surdos ainda apresentam dificuldades com o texto escrito em Língua Portuguesa, mas essas dificuldades são em diferentes níveis. Maria, com maior domínio da Língua Portuguesa e João com dificuldades mais acentuadas, sobretudo, no que diz respeito aos gêneros acadêmicos.

Desta forma, vê-se que, ao tratar-se de uma segunda língua (L2) em uma perspectiva bilíngue, não é necessário que os aprendizes de L2 cheguem aos níveis mais avançados de proficiência nessa segunda língua. Como eles utilizam sua língua materna, usam sua língua automaticamente, involuntariamente em qualquer situação, até em situações que não exigem processamento linguístico (MATTOS, 2000, p. 68). Neste caso, a dificuldade de domínio é quase uma consequência desse tipo de bilinguismo.

A partir dessa pesquisa, foi possível compreender que o fato de os sujeitos não dominarem de forma proficiente a Língua Portuguesa na modalidade escrita, não interferiu a permanência e o sucesso acadêmico dos surdos envolvidos nessa pesquisa quando imersos em um contexto educativo universitário em que a Libras é priorizada. Mesmo com as dificuldades na Língua Portuguesa escrita, eles conseguiram ingressar na Educação Superior, em nível de graduação e, posteriormente, na pós-graduação e apresentar desempenho acadêmico compatível com a complexidade exigida em tais níveis de educação, muito embora as práticas de letramento 
dos sujeitos e a transmissão de capital cultural tenham se revelado um diferencial nesse processo para o domínio da L2.

\section{REFERÊNCIAS}

BAKHTIN, M. M. Estética da criação verbal. Trad. Paulo Bezerra. 6. ed. São Paulo: WMF Martins Fontes, 2015 [1979].

BOTELHO, P. Surdos Oralizados e identidades surdas. In: SKLIAR, C. (Org.). Atualidade da educação bilíngue para surdos: interfaces entre pedagogia e Linguística. Porto Alegre: Editora Mediação, 2016. cap. 11, p. 151-168.

BOURDIEU, P. (Org). A miséria do mundo. Petrópolis, RJ: Vozes, 2001.

BOURDIEU, P. Escritos de educação. Petrópolis: Vozes, 1998.

BOURDIEU, P. Homo academicus. Trad. Ione Ribeiro Valle; Nilton Valle. Rev. Téc. Maria Tereza de Queiroz Piacentini. Florianópolis: Ed. da UFSC, 2011.

BOURDIEU, P. O poder simbólico. 5. ed. Rio de Janeiro: Bertrand Brasil, 2002.

BOURDIEU, P.; PASSERON, J. Os herdeiros: os estudantes e a cultura. Florianópolis: Ed. da UFSC, 2014[1964].

BRASIL. Lei n. 13.146, de 06 de julho de 2015. Institui A Lei Brasileira de Inclusão da Pessoa Com Deficiência: (Estatuto da Pessoa com Deficiência). Brasília, DF, 07 jul. 2015. Disponível em: http://www.planalto.gov.br/ccivil_03/_ato2015-2018/2015/Lei/L13146.htm. Acesso em: 25 nov. 2017.

BRASIL. Ministério da Educação. Decreto n. 5.626, de 22 de dezembro de 2005. Regulamenta a Lei n. 10.436, de 24 de abril de 2002, Que Dispõe Sobre A Língua Brasileira de Sinais - Libras, e O Art. 18 da Lei no 10.098, de 19 de dezembro de 2000. Brasília, DF: MEC, 23 dez. 2005. Disponível em: http://www.planalto.gov.br/ccivil_03/_ato20042006/2005/decreto/d5626.htm. Acesso em: 14 out. 2017.

BRASIL. Ministério da Educação. Lei n. 10.436, de 24 de abril de 2002. Dispõe Sobre A Língua Brasileira de Sinais - Libras e Dá Outras Providências. Brasília, DF: MEC, 25 abr. 2002. Disponível em: http://www.planalto.gov.br/ccivil_03/leis/2002/110436.htm. Acesso em: 07 dez. 2017.

DAROQUE, S.; PADILHA, A. M. Alunos surdos no ensino superior: uma discussão necessária. Piracicaba: Comunicações, 2012.

ESDRAS, D.; GALASSO, B. Panorama da Educação de surdos no Brasil ensino superior. Rio de Janeiro: Instituto Nacional de Educação de Surdos, 2017.

FISCHER, A. A construção de letramentos na esfera acadêmica. 2007. $341 \mathrm{f}$. Tese (Doutorado) - Centro de Comunicação e Expressão, Universidade Federal de Santa Catarina, 
Florianópolis, 2007. Disponível em:

https://repositorio.ufsc.br/xmlui/handle/123456789/89764. Acesso em: 23 out. 2019.

GOLDFELD, M. A criança surda: linguagem e cognição numa perspectiva sociointeracionista. 2. ed. São Paulo: Plexus, 2002.

GUARINELLO, A. C. et al. Surdez e letramento: pesquisa com surdos universitários de Curitiba e Florianópolis. Marília: Bras. Ed. Esp., 2009.

INAF. INSTITUTO PAULO MONTENEGRO (Org.). Indicador de alfabetismo funcional: Estudo especial sobre alfabetismo e mundo do trabalho. São Paulo, 2016.

LAHIRE, B. Sucesso escolar nos meios populares. São Paulo: Editora Ática, 1997.

LODI, A. C. B. Plurilingüismo e surdez: uma leitura bakhtiniana da história da educação dos surdos. Educação e Pesquisa, São Paulo, v. 31, n. 3, p. 409-424, 2005.

MATTOS, A. A hipótese universal e a aquisição da 2a língua. Rev. Est. Ling., Belo Horizonte, 2000.

PEREIRA, M. C. Leitura, escrita e surdez. CENP/CAPE. São Paulo: FDE, 2009.

PERLIN, G. Alternativas metodológicas para o aluno surdo. Santa Maria: UFSM, 2006.

QUADROS, R. Ideias para ensinar português para surdos. Brasília: MEC, SEESP, 2006.

ROJO, R. Letramento e capacidade de leitura para a cidadania. São Paulo: SEE/CENEP, 2004.

SANTANA, A. P. A Edição de Livros em Língua de Sinais no Brasil e na França: implicações para o acesso do surdo à cultura escrita. Revista Portuguesa de História do Livro, v. 37-38, p. 311-344, 2016.

SANTANA, A. P. Surdez e linguagem: aspectos e implicações neurolinguisticas. São Paulo: Plexus, 2013.

SANTANA, A. P.; CARNEIRO, M. S. C. O Processo de Avaliação da Aprendizagem do Surdo no Contexto da Escola Regular. In: GIROTO, C. R. M.; MARTINS, S. E. S. O.; BERBRIAN, A. P. (Org.). Surdez e educação inclusiva. São Paulo: Cultura Acadêmica; Marília: Oficina Universitária, 2012. Disponível em: https://www.marilia.unesp.br/Home/Publicacoes/afv7_obraindividual_giroto_martins_berberian_2012-pcg.pdf. Acesso em: 23 out. 2019.

SANTANA, A. P.; STOLSKY, M. Atuação fonoaudiológica na educação. In: MARCHESAN, I. Q.; SILVA, H. J.; TOMÉ, M. C. (Org.). Tratado das especialidades em fonoaudiologia. 1. ed. São Paulo: Pylar, 2014. p. 488-496.

SETTON, M. Um novo capital cultural: predisposições e disposições à cultura informal nos segmentos com baixa escolaridade. Educ. Soc., Campinas, v. 26, n. 90, p. 77-105, 2005. ISSN 1678-4626. DOI: https://doi.org/10.1590/S0101-73302005000100004 


\section{Como referenciar este artigo}

DARDE, A. O. G.; SANTANA, A. P. O. Letramento de surdos universitários no Brasil: o bilinguismo em questão. Revista Ibero-Americana de Estudos em Educação, Araraquara, v. 16, n. 2, p. 761-782, abr./jun. 2021. e-ISSN: 1982-5587. DOI: https://doi.org/10.21723/riaee.v16i2.13118

Submetido em: 14/09/2019

Aprovado em: $16 / 11 / 2019$

Publicado em: 01/02/2021 